\title{
A champion of organismal biology
}

\author{
Ken Cheng $\cdot$ Bernhard Ronacher
}

Received: 16 March 2015 / Revised: 17 March 2015 / Accepted: 18 March 2015 / Published online: 5 April 2015

(C) Springer-Verlag Berlin Heidelberg 2015

This special issue on Insect orientation and navigation honours the life and work of Rüdiger Wehner, a frequent contributor to this journal and a champion of organismal biology. The occasion prompting this initiative was his 75th birthday, celebrated with his wife Sibylle Wehner in Sydney, Australia, in February while he was visiting one of us $(\mathrm{KC})$ to collaborate on writing a paper and planning research on a new grant. A one-day symposium on Ecology, sensory processes, and cognition was also held in his honour at Macquarie University during that visit.

Rüdiger Wehner obtained his Ph.D. in 1967 under the supervision of Martin Lindauer at the University of Frankfurt, where one of his fellow students was Randolf Menzel. He became an assistant at the University of Zurich in 1967, before becoming Assistant Professor in 1970, and Full Professor in 1974. He has remained in Zürich ever since, with a long stint of dedicated service as the Head of the Zoologisches Institut (Department of Zoology). After becoming Professor Emeritus, he obtained a von Humboldt Award to collaborate with Wolfgang Rössler at the University of Würzburg, a post that he has half-jokingly characterised as a post-professorial fellowship. To date, the collaboration is continuing on a series of research grants. He has had many collaborators over the years, including both of us guest editors, who owe chunks of our research career to our collaborations with him.

We need not give details of his professional career, as Rüdiger Wehner himself has done that recently (Wehner

\section{K. Cheng $(\bowtie)$}

Macquarie University, Sydney, NSW, Australia

e-mail: ken.cheng@mq.edu.au

\section{B. Ronacher}

Institute for Biology, Humboldt Universität zu Berlin,

Berlin, Germany
2013). He has been invited to give a good number of named lectures across Europe, in the USA, and in India. And he has won his share of scientific prizes. These include the Karl Ritter von Frisch Medal from Germany (1994), the Marcel Benoist Prize from Switzerland (2002), and the King Faisal International Prize for Science from Saudi Arabia (2008). Among his many students over the years, 12 have attained full professorship, while one heads research at Novartis Pharmaceuticals, and one directs the Hansekolleg (Institute of Advanced Study in northern Germany).

Rüdiger Wehner has of course contributed much to the study of insect orientation and navigation. Our understanding of the polarisation compass, other compasses, path integration, the concept of matched filter (Wehner 1987), the use of landmarks by insects, and searching behaviour in ants have all benefitted from his contributions. We again need not give any more details here, as the first paper in this issue, by Cheng and Freas (2015), discuss this scientific legacy.

Next comes another review on a topic that Rüdiger Wehner has studied a lot: path integration. Mandyam Srinivasan, who has collaborated with Wehner on seminal work on the topic (Wehner and Srinivasan 1981, 2003), reviews path integration in bees and ants (Srinivasan 2015), two groups of animals that Wehner has studied. The directional component of path integration (a compass), the distance component (odometry), as well the integration component (putting direction and distance together to come up with a vector) are all discussed.

In another review, on honeybees and their use of landmark information, Randolf Menzel and Uwe Greggers present what they suggest is cognitive mapping in bees (Menzel and Greggers 2015). The process is taken to work on travels over longer distances, other orienting mechanisms such as view matching playing a role closer to the goal. 
The ideas are some of the most detailed from Menzel's group on this concept, although the authors admit that the evidence is not definitive as yet. Rüdiger Wehner is likely to disagree with the main thesis. But we see a 'disagreeing' paper still as a paper in honour. Science can only advance by hearing all views openly, and not shutting down continuing dialogue. The hope is that from thesis and antithesis can come a new synthesis.

To which degree insects that are displaced rely on landmarks or the panorama cues obviously depends on the navigational information provided by their respective habitats. The paper by Stürzl and coworkers presents a promising method to quantify such information by constructing a 3D model of the natural environment based on a combination of laser scans and overlapping pictures obtained by a camera (Stürzl et al. 2015). This approach will be a prerequisite for testing visual navigation algorithms under nearly 'reallife' conditions. The paper by Ardin et al. (2015) addresses a so far neglected problem for navigation that relies on visual memories of the surroundings: the image distortions caused by variation in head pitch if ants run over uneven ground. Since there is no evidence for head stabilisation in Cataglyphis velox, homing performance may be drastically affected by such image distortions.

Next come a series of original papers on Cataglyphis fortis, a North African desert ant that has been much studied by Wehner and his collaborators over the years. The paper by Fleur Lebhardt and Bernhard Ronacher focuses on the ants' celestial compass cues, asking whether a transfer of directional information is possible between the sun compass and the polarisation compass (Lebhardt and Ronacher 2015). Ants were trained to a feeder while they had only sun compass information available, and their homing direction was observed when only the polarisation compass was available, or vice versa. Their results demonstrate that the transfer is possible in both directions. Roman Huber and Markus Knaden present data on path integration in $C$. fortis (Huber and Knaden 2015). Their paper documents how the ant fares in path integration over very long journeys, and also investigates the role of panoramic cues in this process. Father and son Thomas and Matthew Collett collaborated with Rüdiger on this species in the past, but have branched out to their own studies of this species. Their paper (Collett and Collett 2015) concerns the influence of path integration, more particularly the global vector, on recapitulating a route. The authors call it a coda to their earlier collaboration with Bisch and Wehner on the concept of a local vector (Collett et al. 1998). The current paper shows in some detail how memory of a route segment and memory of global path integration can interact. Another aspect in the study of $C$. fortis is their search behaviour. This is featured in Siegfried Bolek and Harald Wolf's contribution (Bolek and Wolf 2015). Their paper focuses on searches for food, and reveals some surprising findings when guiding structures such as an alley of landmarks pave the way to the food source. Christoph Zollikofer, one of Rüdiger's illustrious students, studied the stepping patterns of four different Cataglyphis species 20 years ago (Zollikofer 1994a, b, c). Verena Wahl, Sarah Pfeffer, and Matthias Wittlinger continue this tradition in $C$. fortis in great 'podometric' detail (Wahl et al. 2015). They examine various parameters of the stepping patterns at different speeds, as well as how the ants attain high speeds by their version of sprinting, running from leap to leap.

The term "champion of organismal biology" is borrowed from the title of one of Rüdiger Wehner's many papers on the polarisation compass (Wehner 1994). Beyond a review, the paper offered philosophical arguments for "fervour for an organismic-centred, rather than a purely problem-centred approach" (p. 139). Rüdiger argued for a "multidisciplinary organismic approach" (p. 103) for trying to solve problems in neuroethology. To him, raising the right questions about a task such as using polarised light for a compass needs "a full appreciation and understanding of the physiological, behavioural and ecological context, within which the nervous system must solve a particular task" (abstract, p. 103). The warning is that focusing solely on how a physicist or an engineer might solve the problem might not even get us close to the solution that has evolved in an animal. Beyond physics and computational work, ethology, cell biology, developmental biology, ecophysiology, and behavioural ecology, among others, might all play a role. We hope that this special issue will stimulate young scientists to continue this tradition of organismal biology.

\section{References}

Ardin P, Mangan M, Wystrach A, Webb B (2015) How variation in head pitch could affect image matching algorithms for ant navigation. J Comp Physiol A 201(6). doi:10.1007/s00359-015-1005-8

Bolek S, Wolf H (2015) Food searches and guiding structures in North African desert ants, Cataglyphis. J Comp Physiol A 201(6). doi:10.1007/s00359-015-0985-8

Cheng K, Freas CA (2015) Path integration, views, search, and matched filters: The contributions of Rüdiger Wehner to the study of orientation and navigation. J Comp Physiol A 201(6). doi: 10.1007/s00359-015-0984-9

Collett TS, Collett M (2015) Route segment odometry and its interactions with global path integration. J Comp Physiol A 201(6). doi:10.1007/s00359-015-1001-z

Collett M, Collett TS, Bisch S, Wehner R (1998) Local and global vectors in desert ant navigation. Nature 394:269-272

Huber R, Knaden M (2015) Egocentric and geocentric navigation during extremely long foraging paths of desert ants. J Comp Physiol A 201(6). doi:10.1007/s00359-015-0998-3

Lebhardt F, Ronacher B (2015) Transfer of directional information between the polarization compass and the sun compass in desert ants. J Comp Physiol A 201(6). doi:10.1007/s00359-014-0928-9 
Menzel R, Greggers U (2015) The memory structure of navigation in honeybees. J Comp Physiol A 201(6). doi:10.1007/ s00359-015-0987-6

Srinivasan MV (2015) Where paths meet and cross: navigation by path integration in the desert ant and the honeybee. J Comp Physiol A 201(6). doi:10.1007/s00359-015-1000-0

Stürzl W, Grixa I, Mair E, Narendra A, Zeil J (2015) Three-dimensional models of natural environments and the mapping of navigational information. J Comp Physiol A 201(6). doi:10.1007/ s00359-015-1002-y

Wahl V, Pfeffer SE, Wittlinger M (2015) Walking and running in the desert ant Cataglyphis fortis. J Comp Physiol A 201(6). doi:10.1007/s00359-015-0999-2

Wehner R (1987) 'Matched filters'-neural models of the external world. J Comp Physiol A 161:511-531

Wehner R (1994) The polarization-vision project: championing organismic biology. Fortschritte Zoologie 39:103-143
Wehner R (2013) Life as a Cataglyphologist—and beyond. Annu Rev Entomol 58:1-18

Wehner R, Srinivasan MV (1981) Searching behaviour of desert ants, genus Cataglyphis (Formicidae, Hymenoptera). J Comp Physiol A 142:315-338

Wehner R, Srinivasan MV (2003) Path integration in insects. In: Jeffery KJ (ed) The neurobiology of spatial behaviour. Oxford University Press, Oxford, pp 9-30

Zollikofer CPE (1994a) Stepping patterns in ants. 1. Influence of speed and curvature. J Exp Biol 192:95-106

Zollikofer CPE (1994b) Stepping patterns in ants. 2. Influence of body morphology. J Exp Biol 192:107-118

Zollikofer CPE (1994c) Stepping patterns in ants. 3 Influence of load. J Exp Biol 192:119-127 